\title{
Sakari Vainikka
}

\section{Antiikin säveljärjestelmät}

Antiikin kreikkalaisen musiikinteorian suuri systeemi oli rakennettu tetrakordeista, jotka seurasivat toisiaan joko peräkkäisinä tai yhden sävelen osalta ahtona. Jokaisella systeemin tetrakordilla ja myös yksittäisellä sävelellä oli oma erisnimensä (Kuva 1.).

Kuva 1.

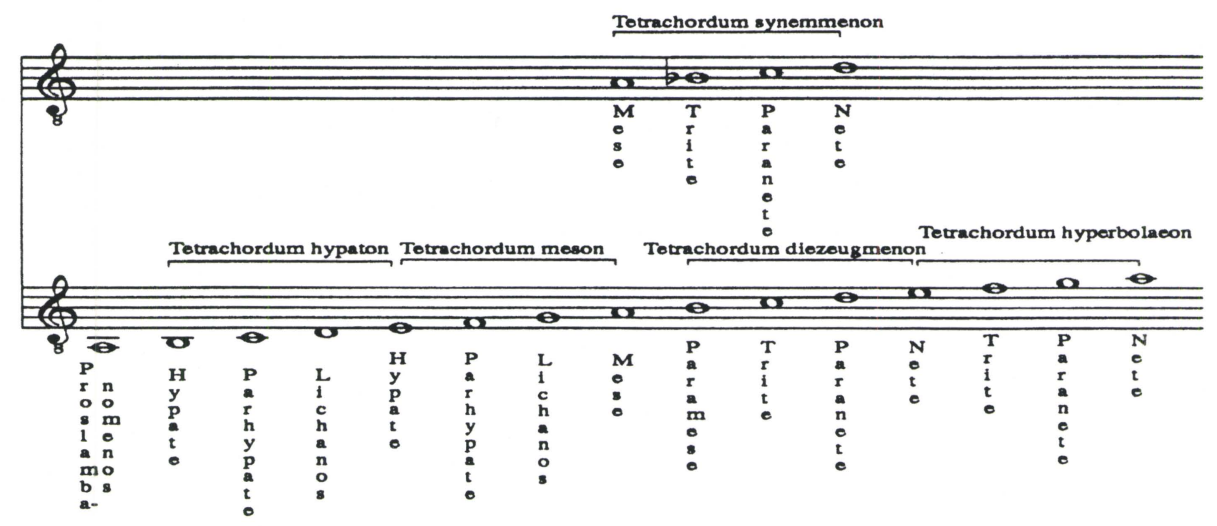

Kuitenkin systeemin sisällä sävelet saivat eri merkityksen sen mukaan, mihin genreen ne kuuluivat. Nämä genret eli viritysjärjestelmät oli ryhmitelty kolmeen pääkategoriaan, diatoniseen, kromaattiseen ja enharmoniseen. Tetrakordien alin ja ylin sävel, siis nykynimillä puhtaan kvartin päässä toisistaan olevat sävelet h-e ja e-a olivat kaikissa genreissä samat, mutta tetrakordien sisälle sijoittuvien sävelten, siis c:n, d:n, f:n ja g:n sävelkorkeudet vaihtelivat eri genreissä. Klassillisissa teksteissä, kuten Platonin Valtiossa ja Aristoteleen Politiikassa moodeista puhutaan monikossa: "[j]otkut fryygiset, jotkut dooriset..." Tämä selittyy luontevasti siten, että antiikin teksteissä tarkoitettiin asteikkojen eri genrejä. Antiikista periytyviä säveljärjestelmien tarkkoja kuvauksia on niukalti. Aristoksenoksen, Ptolemaioksen ja Boethiuksen kuvaukset ovat säilyneet. Ensiksi mainitut on tradeerannut latinankieliseen Eurooppaan 1500-luvun maineikas italialainen teoreetikko Girolamo Mei. Boethiuksen 500-luvun alussa kirjoittamaan teoriaan viitataan useissa keskiaikaisissa lähteissä. Seuraavassa esityksessä lähteenä on käytetty 800- ja 900-lukujen taitteessa eläneen flaamilaisen munkki Hucbaldin teosta De Musica, jonka monokordiin sijoitettu suhdejärjestelmä perustuu Boethiuksen 
teksteihin. Boethiuksen ja Hucbaldin mallin mukainen monokordin kaavio on rekonstruoitu Martin Gerbertin klassikossa Scriptores ecclesiastici de musica sacra potissimum vuodelta 1784 (vol. 1, s. 122 lisälehti).

Gerbertin esittelemässä kaaviossa on käytetty monokordin kieltä kuvaavia janoja. Sen sijaan seuraavissa kaavioissa Boethius-Hucbaldin monokordin määrittelemät kreikkalaisen suuren systeemin sävelet on sijoitettu havainnollisuuden vuoksi nuottiviivastoille (Kuva 2.). Diatonisen asteikon yhteydessä sekä useiden kromaattisten ja enharmonisten sävelten yläpuolella sävelet on esitetty kirjainsymboleina. Eri säveljärjestelmien samoja säveltasoja ei välttämättä ole esitetty omana kirjainsymbolinaan. Kaavion alalaidassa on lisäksi C:stä alkava oktaavin mittainen diatonisen asteikon kirjainnimistö, joka noudattaa aakkosten järjestystä (Taulukko 1.). ${ }^{1}$ Se on selkeyden vuoksi tästä esityksestä jätetty pois. Kirjainten jälkeiset pisteet on otettu suoraan kaaviosta: se että piste puuttuu joistakin kohdista, on ilmeisesti Hucbaldin tai Gerbertin lapsus. Myös sävelten kreikkalaisen systeemin mukaisten nimien, kirjainsymbolien ja roomalaisten numeroiden merkitsemisessä esiintyy epäjohdonmukaisuutta, mikä ei kuitenkaan estä niiden tulkitsemista.

Kaaviossa on mukana Tetrachordum synemmenon (Hucbaldilla synnemenon), joka tässä esitetään erillisenä kuvana (Kuva 3. ja Taulukko 2.). Hucbald on lisännyt A:sta ja D:stä alkavat tetrakordit klassillisen tetrakordiston oheen. Suuren systeemin mukaiset sävelten nimet ja intervallien laajuutta kuvaava kokonaislukujen sarja, jotka Hucbaldin esityksessä on sijoitettu itse kaavioon, esitetään seuraavassa kahtena erillisenä taulukkona.

Kuva 2.

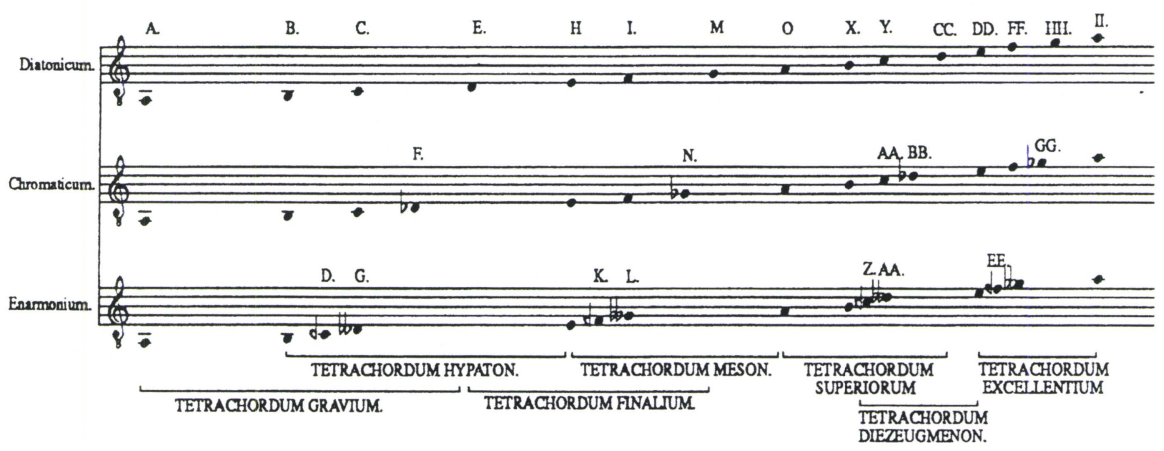

\footnotetext{
${ }^{1}$ Tässä vaihtoehtoisessa sävelnimisysteemissä Hucbald merkitsee Parhypate hypatonin ja trite diezeugmenonin aakkosten ensimmäisellä kirjaimella A. Mielenkiintoinen havainto on, että jo tässä vaiheessa sävel, jonka nimeksi sittemmin vakiintui $C$, on tällä tavalla nostettu eräänlaiseksi systeemin perussäveleksi. $\mathrm{Se}$, että monokordin sävelnimistön alun kirjaimilla A, B ja C tarkoitetaan samoja säveliä kuin anglosaksisessa traditiossa nykyisinkin, ei johtune Hucbaldin monokordin käyttämistä sävelten kirjainsymboleista: aakkosten mukainen sävelnimistö risteilee tämän alun jälkeen myös kromaattisen ja enharmonisen säveljärjestelmän puolella.
} 
Seuraavissa taulukoissa sävelet esitetään matalimmasta korkeimpaan. Kirjain sävelen nimen perässä ( $d, k$ tai e) tarkoittaa genreä. Jos kirjainta ei ole, sävel on kaikille genreille yhteinen. Roomalaiset numerot ovat suoraan Hucbaldin kaaviosta. Arabialaiset numerot on lisätty helpottamaan kaavion ymmärtämistä. Luvuilla kuvataan monokordin kielen eli aallon pituuden jakosuhteita. Kääntäen ne kuvaavat värähdyslukujen suhteita.

Taulukko 1. Sävelet matalimmasta korkeimpaan ovat seuraavat:

$\begin{array}{llll}\text { A. } & \text { Proslambanomenos } & \text { VIIII.CC.XVI. } & 9216 \\ \text { B. } & \text { Hypate hypaton } & \text { VIII.C.XC.II. } & 8192 \\ \text { C. } & \text { Parhypate hypaton (d, k) } & \text { VII.DCC.LXXVI } & 7776 \\ \text { D. } & \text { Parhypate hypaton (e) } & \text { VII.DCCCC.LXXXIIII } & 7984 \\ \text { E. } & \text { Lychanos hypaton (d) } & \text { VI.DCCCC.XII } & 6912 \\ \text { F. } & \text { Lychanos hypaton (k) } & \text { VII.CC.XCVI } & 7296 \\ \text { G. } & \text { Lychanos hypaton (e) } & \text { VII.DCC.LXXVI. } & 7776 \\ \text { H. } & \text { hypate meson } & \text { VI.C.XLIIII } & 6144 \\ \text { I. } & \text { parhypate meson (d, k) } & \text { V dCCC.XXX.II } & 5832 \\ \text { K. } & \text { parhypate meson (e) } & \text { V dCCCC.LXXX.VIII } & 5988 \\ \text { L. } & \text { lychanos meson (e) } & \text { V.dCCC.XXX.II. } & 5832 \\ \text { M. } & \text { lychanos meson. (d) } & \text { V.C.LXXX.IIII. } & 5184 \\ \text { N. } & \text { lychanos meson. (k) } & \text { V.CCCC LXX.II. } & 5472 \\ \text { O. } & \text { mese } & \text { IIII.dC.VIII } & 4608 \\ \text { X. } & \text { paramese. } & \text { IIII.XC.VI. } & 4096 \\ \text { Y. } & \text { trite diezeug. (d) } & \text { III.dCCC.LXXX.VIII. } & 3888 \\ \text { Z. } & \text { trite diez (e) } & \text { III.dCCCC.XC.II. } & 3992 \\ \text { AA. } & \text { trite diezeug. (k) } & \text { III.dCCC.LXXX VIII. } & 3888 \\ \text { AA. } & \text { paranete diezeug (e) } & \text { III.dCCC.LXXX.VIII. } & 3888 \\ \text { BB. } & \text { paranete diezeug. (k) } & \text { III.dC.XL.VIII. } & 3648 \\ \text { CC. } & \text { paranete diezeug. (d) } & \text { III.CCCC.L.VI. } & 3456 \\ \text { DD } & \text { nete diezeug. } & \text { III.LXX.II. } & 3072 \\ \text { EE. trite hyperb. (e) } & \text { II dCCCC.XC IIII } & 2994 \\ \text { FF. } & \text { trite hyperb. (d, k) ja } & & \\ & \text { paranete hyperb. (e) } & \text { II.dCCCC.XVI. } & 2916 \\ \text { GG. } & \text { paranete hyperb (k) } & \text { II dCC.XXX.VI. } & 2736 \\ \text { HH. } & \text { paranete hyperb (d) } & \text { II.d.XC.II. } & 2304 \\ \text { II. } & \text { nete hyperb. } & \text { II.CCC.IIII. } & \end{array}$


Kuva 3. Tetrachordum synemmenon:

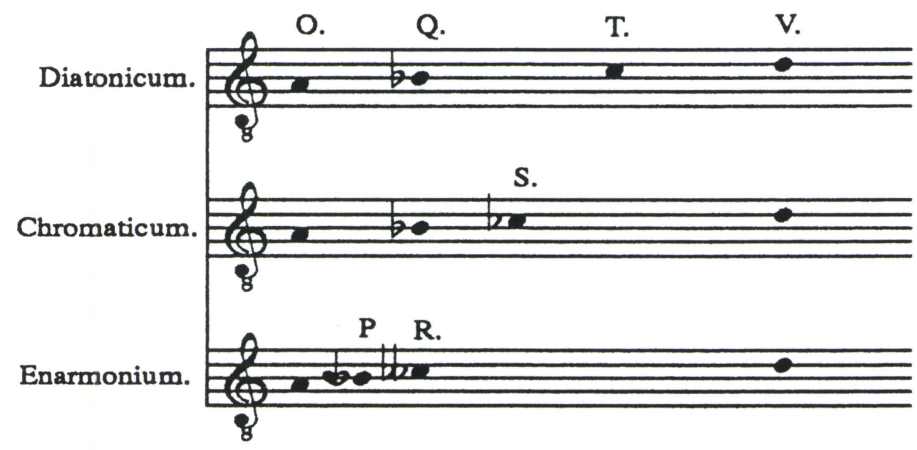

Taulukko 2. Sävelet matalimmasta korkeimpaan:

O. Mese

P trite synnem (e)

Q. trite synnem $(\mathrm{d}, \mathrm{k})$

R. paranete synnem (e)

S. paranete synnem. $(\mathrm{k})$

T. paranete synnem. (d)

$\mathrm{V}$. nete synnemenon.
IIII.dC.VIII 4608

III.CCCC.XC.I 4491

IIII.CCC.LXX.IIII. $\quad 4374$

IIII.CCC.LXX.IIII. $\quad 4374$

IIII C.IIII. $\quad 4104$

III.dCCC.LXXX.VIII. $\quad 3888$

III.CCCC.L.VI. 3456

\section{Tetrakordien rakenne}

Pienin kokonaislukujen joukko, joka sisältää Boethius-Hucbaldin diatonisen tetrakordin lukusuhteet, on 192:216:243:256. Tämä suhteisto esiintyy ajanlaskumme alkuvuosikymmeninä eläneen Plutarkhoksen kirjoituksissa. Plutarkhos viittaa useissa kohdissa kreikkalaisen musiikin historiaan ja perustaa käsityksensä luotettavien auktoriteettien, kuten Aristoksenoksen teksteihin. Tetrakordin puolisävelaskel muodostuu suhteesta 256:243 (90 senttiä), kokosävelaskeleiden suhteet ovat 9:8 (204 senttiä), pieni terssi 32:27 (294 senttiä), suuri terssi 81:64 (408 senttiä) ja kvartti 4:3 (498 senttiä).

Kromaattisessa tetrakordissa alempi pieni sekunti, suuri terssi ja kvartti ovat samat kuin diatonisessa asteikossa. Alhaalta lukien ensimmäisen ja kolmannen sävelen ero on 64:57 (200,5 senttiä). Tetrakordin toisen ja kolmannen sävelen ero on 81:76 (110 senttiä). Kromaattisen tetrakordin ylinousevan sekunnin suhdeluku on 19:16 (297,5 senttiä). Tämä on sama kuin yläsävelsarjan perussävelen oktaavikerrannaisen ja sen yläpuolisen osasävelen tuottama puhdas pieni terssi.

Enharmonisessa tetrakordissa puolisävelaskel $(256: 243)$ on puolitettu suhteessa 512:499:486. Alimman ja toisen sävelen ero on 512:499 (44,5 senttiä). Toisen ja kol- 
mannen sävelen ero on 499:486 (45,5 senttiä). Puolitus on tehty aritmeettisen keskiarvon mukaisesti. Sen vuoksi alempi intervalli on sentin kapeampi kuin ylempi. Alhaalta lukien toisen sävelen suhde tetrakordin ylimpään säveleen on 499:384 (453,5 senttiä). Tetrakordin ylimpien sävelten muodostama kaksinkertaisesti ylinouseva sekunti on enharmoninen diatonisen ja kromaattisen tetrakordin suuren terssin kanssa (81:64, 408 senttiä). Enharmonisen tetrakordin alhaalta lukien toisen sävelen ja kromaattisen tetrakordin kolmannen sävelen ero on 499:456 (156 senttiä).

Lähes kaikki Hucbaldin monokordiin kirjaamat luvut ovat jaollisia sekä 3:lla että 2:1la. Poikkeuksia ovat Hypate hypaton (8192), enharmonisen asteikon Parhypate hypaton (7984), paramese (4096) ja enharmonisen asteikon trite diez (3992), jotka ovat jaollisia vain 2:lla. Tämä johtuu siitä, että tetrakordien äärisävelten puhdas kvartti laskettiin ylhäältä alas laskukaavalla $4 x / 3$. Systeemin matalimpien sävelten alakvarttia ei tarvittu, jolloin niitä kuvaavat luvut saattoivat olla jaollisia vain 2:lla. Paramesen (sävel h:n) alakvarttia taas ei ollut koko systeemissä. Kun sävelten erotusta kuvaavat suhdeluvut supistetaan pienimpiin arvoihinsa, lukujen joukossa on kolme alkulukua, jotka ovat jaollisia vain yhdellä ja itsellään: 3, 19 ja 499 .

Girolamo Mei esittelee teoksessa De modis Boethiuksen lisäksi Ptolemaioksen (n. 85-163) ja Aristoksenoksen (s. n. 370 eKr) systeemit. Nämä olivat hienojakoisempia kuin Boethiuksen. Ptolemaioksella on viisi erilaista diatonista suhteistoa, kaksi kromaattista ja yksi enharmoninen. Aristoksenoksella on kaksi diatonista, kolme kromaattista ja yksi enharmoninen järjestelmä. Ptolemaioksella diatonisen säveljärjestelmän tetrakordit, joita Mein tekstissä kutsutaan nimellä intenti diatoni, on rakennettu seuraavasti: puolisävelaskel on 16:15 (112 senttiä), vahva kokosävelaskel on 9:8 (204 senttiä) ja heikko kokosävelaskel 10:9 (182 senttiä). Seuraavan genren tetrakordit, toniaei diatoni, muodostuvat siten, että erittäin suppeaa puolisävelaskelta 28:27 (63 senttiä) seuraa laaja kokosävelaskel 8:7 (231 senttiä) ja ylimpien sävelten ero on puhdas suuri sekunti 9:8 (204 senttiä). Mollis diatoni -genren intervallit alhaalta lukien ovat 21:20 (85), 10:9 (182) ja 8:7 (231) senttiä. Intenti chromatis on alhaalta lukien 22:21 (81), 12:11 (150) ja 7:6 (267) senttiä. Mollis chromatis sisältää Mein laskelmissa virheen. Tekstin mukaan se muodostuu alhaalta lukien suhteista 24:23, 15:14 ja 6:5. Näistä syntyy yhteensä kvartti, jonka laajuus on 509 senttiä. Oikea tulos saavutettaisiin, jos alempi puolisävelaskel olisi sama kuin toniaei diatoni -genressä. Näin laskien mollis chromatis -genren tetrakordi muodostuu alhaalta lukien seuraavasti: $63,119 \mathrm{ja}$ 316 senttiä. Enharmoninen genre, enharmonii generis, muodostuu Ptolemaioksella seuraavasti: pienin sävelaskel on 46:45 (38 senttiä), seuraava 24:23 (74 senttiä) ja suurin sävelaskel on 5:4 (386 senttiä), siis enharmoninen suuren terssin kanssa. Ero Boethiukseen nähden on siinä, että Ptolemaioksella tämä intervalli on enharmoninen yläsävelsarjan mukaisen puhtaan terssin kanssa, kun taas Boethiuksella kysymyksessä on pythagoralainen suuri terssi. Ptolemaioksen systeemin johdonmukaisuus näkyy tetrakordien ylimmän intervallin muutoksissa: ne alkavat heikosta kokosävelaskeleesta 
10:9 ja laajenevat askel kerrallaan kohti puhdasta terssiä (9:8, 8:7, 7:6, 6:5 ja 5:4).

Aristoksenoksen järjestelmä on Mein tekstissä kuvattu lukusuhteina, jotka eivät nouse yläsävelsarjasta. Näyttää siltä, että Aristoksenos ei ole pitäytynyt myöskään pythagoralaiseen matemaattiseen strukturalismiin, vaan on esittänyt eräänlaisen havaintopsykologisen suhteiston. Aristoksenos jakaa kvartin 60 osaan ja muodostaa eri genret tältä pohjalta. Aristoksenoksen suhdeverkoston muuttaminen vakiintuneen logaritmisen senttijärjestelmän mukaiseksi pitäisi todennäköisesti tehdä siten, että käytettäisiin kertoimena lukua 8.3 (498/60). Käyttökelpoisempi laskutapa on kuitenkin tässä tapauksessa sellainen, jossa puhtaan kvartin senttiluvuksi otetaan tasaluku 500. Tällöin saadaan aikaan puhtaan kvartin sisällä olevien sävelten havainnollinen kuvaus, jossa jokaisen tasavireisen puolisävelaskelen mitta on 100 senttiä. Diatoni intenti -genren tetrakordi muodostuu puolisävelaskeleesta ja kaksi kertaa niin suurista kokosävelaskeleista, (12:24:24), sentteinä ilmaistuna 100, 200 ja 200. Toinen diatoniseksi määritelty tetrakordi, diatoni mollis muodostuu kahdesta erisuuruisesta puolisävelaskeleesta ja puolen kvartin laajuisesta kokosävelaskeleesta (12:18:30), sentteinä 100, 150 ja 250. Chromatis toniaein lukusuhteet ovat 12:12:36, sentteinä 100, 100 ja 300. Chromatis hemiolii -tetrakordin suhdeluvut ovat 9:9:42, sentteinä 75, 75 ja 350. Chromatis mollis -tetrakordin suhdeluvut ovat 8:8:44, sentteinä 67,67 ja 366. Enharmonii generis -tetrakordin suhdeluvut ovat 6:6:48, sentteinä 50, 50 ja 400. Aristoksenos tuli esittäneeksi eräänlaisen tasavireisen mallin, jossa intervallien jakosuhteet hahmotetaan kuulohavainnon, ei geometrian pohjalta.

Kolme musiikin historiassa vaikuttanutta viritysjärjestelmää, pythagoralainen, yläsävelsarjaan perustuva puhdas ja tasavireinen viritys saivat omat teoriansa jo antiikin aikana. On vaikea arvioida, kuinka lähellä antiikin musiikkikäytäntöjä nämä matemaattiset mallit ovat olleet. Joka tapauksessa säveljärjestelmien teoreettisista kuvauksista saa käsityksen musiikkikulttuureista, jotka ovat sisältäneet valtavan mahdollisuuksien kirjon. Erilaisilla hienojakoisilla virityksillä on tavoitettu sellaisia affekteja, joista oman aikamme säveltäjät voivat vain uneksia.

\section{Lähteet}

Gerbert, Martin (1963). Scriptores Ecclesiastici de Musica sacra potissimum. Reprografischer Nachdruck der Ausgabe St. Blasien 1784. Hildesheim: Georg Olms Verlagsbuch-handlung.

Mei, Girolamo (1991). De modis, toim. Tsugami Eisuke. Tokyo: Keiso Shobo, 3-129. (ks. myös: <http:/ /www.music.indiana.edu/tml/16th/MEIMOD_TEXT.html>) 